\title{
EFFECTS OF TRAINING ON BONE METABOLISM IN YOUNG ATHLETES
}

original paper

(1) University School of Physical Education in Wroclaw

DOI: https://doi.org/10.5114/hm.2021.104181

\section{ANTTI M.J. MERO, KEIJO HÄKKINEN, HEIKKI KYRÖLÄINEN, ANTTI A. MERO}

Biology of Physical Activity, Faculty of Sport and Health Sciences, University of Jyväskylä, Jyväskylä, Finland

\begin{abstract}
Purpose. This study investigated the effects of two types of training on the bone formation marker of osteocalcin and the bone resorption marker of tartrate-resistant acid phosphatase isoenzyme $5 \mathrm{~b}$ (TRAP5b) in young track and field boys and girls.

Methods. The 14-year-old group (10 boys, 10 girls) performed first time an intensive and supervised 8-week plyometric training. In the 17-year-old group (13 athletic boys, 6 control boys, 12 athletic girls, 6 control girls), the normal many-sided track and field training lasted 6 months.

Results. Significant increases were noticed in osteocalcin $(p<0.01)$ both in younger boys and girls. The 20-m sprint performance improved in girls $(p<0.01)$ and the countermovement jump height increased in boys $(p<0.001)$. Significant increases in 17-year-old boys and girls were observed after training in osteocalcin $(p<0.01)$, osteocalcin/TRAP5b ratio $(p<0.01$ and $p<0.001)$, and the standing 5-jump $(p<0.05$ and $p<0.01)$. Serum TRAP5b decreased both in boys $(p<0.05)$ and in girls $(p<0.01)$. The boys also improved the standing 5-jump $(p<0.01)$ and the 12-minute running test results $(\mathrm{p}<0.05)$. In the combined group of all subjects, the correlation coefficient between TRAP5b and age was significant $(r=-0.63, p<0.001$, $n=57)$.
\end{abstract}

Conclusions. In practice, it is important to add plyometrics and other strength training in the training plans of young athletes, regardless of their events, to increase their bone metabolism and muscle strength.

Key words: anabolism, exercise, children, puberty

\section{Introduction}

Bone mass is considered as the net product of 2 metabolic processes: formation and resorption. These enable the skeleton to carry out its principal functions of mechanical support to the body [1]. Many factors, such as genetics, nutrition, various hormones, and physical activity, affect or regulate bone metabolism. Several blood and urinary molecules have been identified as markers of bone metabolic activity. Consequently, they provide estimations of the rates and direction of the biological activities governing bone turnover. According to the literature [2], there are 4 serum bone formation markers (osteocalcin, bone alkaline phosphatase, carboxyterminal propeptide of type 1 procollagen, and aminoterminal propeptide of type 1 procollagen), as well as 6 bone resorption markers (in serum: tartrate-resistant acid phosphatase isoen- zyme 5b [TRAP5b] and carboxyterminal cross-linked telopeptide of type 1 procollagen; in serum and urine: pyridinoline and deoxypyridinoline; in urine: carboxyterminal cross-linking telopeptide of type 1 collagen and aminoterminal cross-linking telopeptide of type 1 collagen).

Osteocalcin is a protein synthesized by osteoblasts, odontoblasts, and hypertrophic chondrocytes, and the role of osteocalcin could be transferred from a simple marker of bone formation to hormone-like regulators of energy metabolism. There is a lot of evidence for the utility of osteocalcin as a bone formation marker (e.g. [3]). It was shown that bone mineral density and osteocalcin were higher in decathletes than in the controls [4]. On the other hand, there is good evidence that osteocalcin plays an important role in energy metabolism. Therefore, any change in osteocalcin related to exercise may potentially be considered as adaptation

Correspondence address: Antti A. Mero, Jyväskylän yliopisto, Rautpohjankatu 8 Viveca, 40014 Jyväskylä, Finland, e-mail: antti.a.mero@jyu.fi

Received: May 13, 2020

Accepted for publication: September 15, 2020

Citation: Mero AMJ, Häkkinen K, Kyröläinen H, Mero AA. Effects of training on bone metabolism in young athletes. Hum Mov. 2021;22(4):105-1112; doi: https://doi.org/10.5114/hm.2021.104181. 
A.M.J. Mero, K. Häkkinen, H. Kyröläinen, A.A. Mero, Effects of training on bone

to increased energy requirements in athletes (e.g. [5]). Puberty influences bone growth when accumulation of skeletal mass occurs through linear growth and an increase in bone density with rising testosterone concentration (e.g. [6, 7]). In young adolescent athletes, a brief period of training has positive effects on bone formation markers [8]. TRAP5b is an enzyme and belongs to the family of 5 known members of ubiquitous acid phosphatases [9]. All the cells of the macrophage lineage, including osteoclasts, express high amounts of TRAP5b [10]. Osteoclasts secrete TRAP5b into the bloodstream, and serum concentration and activity of this enzyme are considered to be a potentially useful marker of bone resorption [9]. Concerning bone resorption in childhood and adolescence, there are limited results on TRAP5b [8].

The purpose of the present study was to investigate effects of 2 training periods on osteocalcin and TRAP5b in 2 different experiments: in 14- and in 17-year-old athletics boys and girls. In addition, the testosterone/ cortisol ratio, which can be informative about the general anabolic-catabolic condition of the body, was measured (e.g. [11]). We hypothesized that the osteocalcin/ TRAP5b ratio would describe the anabolic-catabolic ratio in bone tissue and these 2 ratios would have a strong relationship with each other.

\section{Material and methods}

\section{Participants}

The present study was comprised of 2 separate substudies. The subjects in study 1 were young track and field boys ( $n=10$; age: $14.0 \pm 0.9$ years; height: 1.70 $\pm 0.11 \mathrm{~m}$; body mass: $55.8 \pm 11.1 \mathrm{~kg}$; fat: $8.4 \pm 3.6 \%$ ) and girls ( $n=10$; age: $14.1 \pm 1.0$ years; height: $1.64 \pm$ $0.09 \mathrm{~m}$; body mass: $52.6 \pm 9.7 \mathrm{~kg}$; fat: $15.2 \pm 3.2 \%)$. This was the 14-year-old group. In study 2 , the experimental group also consisted of young track and field boys ( $n=13$; age: $16.9 \pm 1.5$ years; height: $1.81 \pm$ $0.08 \mathrm{~m}$; body mass: $66.2 \pm 8.5 \mathrm{~kg}$; fat: $11.3 \pm 1.8 \%$ ) and girls $(n=12$; age: $16.6 \pm 0.8$ years; height: $1.69 \pm$ $0.03 \mathrm{~m}$; body mass: $58.7 \pm 5.9 \mathrm{~kg}$; fat: $24.4 \pm 2.7 \%$ ). This was the 17-year-old group. The control group consisted of 12 high school boys $(n=6$; age: $17.5 \pm 1.0$ years; height: $1.79 \pm 0.05 \mathrm{~m}$; body mass: $74.6 \pm 9.3 \mathrm{~kg}$; fat: $17.3 \pm 3.1 \%)$ and girls $(n=6$; age: $17.8 \pm 0.8$ years; height: $1.66 \pm 0.08 \mathrm{~m}$; body mass: $57.8 \pm 10.8 \mathrm{~kg}$; fat: $27.1 \pm 3.8 \%$ ). The body fat was measured by using the 4-skinfold method [12]. All the participants and their parents (if the participant was under 18 years of age) were aware of the protocol, benefits, and possible risks of the study. They were also advised of their rights to withdraw from the study at any time.

\section{Experimental protocol and training}

In accordance with the present scientific literature and practical coaching findings, we decided to choose 2 age groups. In the younger age group, it will be interesting to see how adding much plyometrics to the training plan affects bone metabolism. In the older age group, the overall training amounts are much bigger and a question is how bone metabolism probably changes.

In study 1 , the participants performed a plyometric training, which lasted 8 weeks, in April and May, with 2 efficient plyometric training sessions of 20-30 minutes a week. They were placed in other 4 track and field training sessions a week, and the plyometric training period was divided into four 2 -week periods. At the beginning of the training, the plyometric training volume was high (200-250 contacts per session), with low intensity. Then, the volume decreased (50150 contacts), while the intensity increased. The exercises used were as follows: standing 3-, 5-, 10-jumps with double leg contacts and alternative contacts (bounding, stepping, and hopping). During the last 4 weeks, the intensity was increased by using double leg hurdle jumps, double leg drop jumps, and stepping and hopping forwards with 2-4-stride speed. The biomechanics of these exercises has been analysed in detail earlier [13]. Before the study period, the technique of the exercises was taught to the participants by their 2 coaches, who also supervised all the plyometric training sessions. The coaches kept diaries of all the training sessions during the study weeks. The other training sessions included sprinting, technique of field events, aerobic running, and stretching exercises. The general nutrition recommendations in Finland were given before the study, but no food diaries were recorded. All the study performance and laboratory measurements were conducted before and after the 8-week period.

In study 2, each athlete trained in accordance with their own training plan and kept a diary on the training and other physical activities. The training volume ranged from 5 to 10 training sessions a week, including sprinting, long distance running, jumping, throwing, weightlifting, etc., depending on the track and field event. Also the training volume, intensity, and frequency varied between different track and field events in terms of technique training and physical training. The control group participants kept a physical activity diary 
concerning their sports activities. They wrote down a rough description of what sports they participated in and how much time they spent for these activities during a 1-week period. Most of the control group had some sports background, but none of them actively exercised or participated in any sports activities. The control boys occasionally went to the gym or ball games. The control girls mostly enjoyed cycling or walking. All training diaries of the athletes were analysed to classify the exercises applied and the training volume.

The measurements for the experimental group were performed before and after the 6 -month training period (October-April). These measurements took place during weekend track and field training camps in the Sports Institute. The control group was also evaluated twice (before and after the study period).

\section{Performance tests}

Study 1 included 2 performance tests: a $20-\mathrm{m}$ sprint test with a flying start and a countermovement jump (CMJ). In study 2, the tests were as follows: a 20-m sprint with a flying start, a standing 5-jump, and a 12-minute running test [14]. The 20 -m sprint test has been shown to be highly reproducible in track and field sprinters, with 2 successive efforts having a correlation coefficient $(r)$ of 0.99 and a coefficient of variation (CV) of $1.2 \%$ [15]. The correlation coefficient between 2 maximal CMJ trials has been shown to be 0.95 , and $C V$ ranged between $4 \%$ and $5 \%$ [16]. The standing 5-jump has not been validated as far as we know, but it is very often used among track and field athletes in Europe and also in young athletes. The relation of the Cooper test to maximal oxygen uptake $\left(\mathrm{VO}_{2} \max \right)$ has been shown to be strong $(r=0.90)$ [14].

On the first testing day, the warm-up consisted of 7-10-minute jogging, stretching exercises, and 3-5 times 30-m acceleration runs. The sprint test consisted of a 30-m maximal acceleration run followed by maximal sprinting over $20 \mathrm{~m}$. Time was measured with photoelectric cells attached to the wall during the last $20 \mathrm{~m}$. Each subject performed this test 2-3 times with a 5-6-minute recovery. The jumping test was different in the 2 studies and was carried out after the sprint test. In study 1 , jumping performance was measured by using CMJ on the contact mat, with hands on the hips, with a timer connected to the mat to calculate the rise of the centre of gravity by using the flight time [17]. In study 2, the maximal standing 5-jump test was performed and the subjects were allowed 1-2 familiarization attempts beforehand. The test included first 1 hop from the standing position, then con- tinuing 3 steps, and finally 1 jump ending to the long jump pit. Totally, 3-4 attempts were done with a recovery of 5-6 minutes. Continuous verbal encouragement was given during all tests.

The second testing day involved an endurance test (Cooper test), consisting of 12-minute running on an indoor 200-m track. The covered distance was recorded.

\section{Blood collection and analysis}

On the first testing day, blood samples $(5 \mathrm{ml})$ were drawn from the antecubital vein after 10-12 hours of fasting in all subjects. Serum samples were kept frozen at $-80^{\circ} \mathrm{C}$ until assayed. Testosterone, cortisol, and osteocalcin were analysed with the Immulite ${ }^{\circledR} 2000$ system (Siemens Medical Solutions Diagnostics, USA). The sensitivity of the assay was $0.5 \mathrm{nmol} / 1$ for serum testosterone, $5.5 \mathrm{nmol} / \mathrm{l}$ for cortisol, and $0.4 \mathrm{ng} / \mathrm{ml}$ for osteocalcin. Between-day precision (CV) was $8.3 \%$ for testosterone, $6.1 \%$ for cortisol, and $3.4 \%$ for osteocalcin. Intra-assay precision (CV) was $5.7 \%$ for testosterone, $4.6 \%$ for cortisol, and $6.3 \%$ for osteocalcin.

In addition to hormone investigation, serum TRAP5b was analysed from the same blood sample. The ELISA method (MicroVue TRAP5b Assay; Quidel Corp., San Diego, USA) was used. For TRAP5b, the sensitivity of the assay equalled $0.2 \mathrm{U} / 1$ and the between-day precision $(\mathrm{CV})$ was $2.0-3.0 \%$. Intra-assay precision $(\mathrm{CV})$ for TRAP5b was under $12 \%$ [18].

\section{Statistical analysis}

Statistical analysis was performed with the SPSS Statistics 17.0 software. The results are presented as mean \pm standard deviation. Normal distributions were checked with the Shapiro-Wilk test. Differences between groups were calculated with paired and unpaired $t$-tests. Pearson's correlation analysis was used to find out correlation coefficients. Statistical significance of the results was accepted at $p<0.05$.

\section{Ethical approval}

The research related to human use has complied with all the relevant national regulations and institutional policies, has followed the tenets of the Declaration of Helsinki, and has been approved by the Ethical Committee of the University of Jyväskylä.

\section{Informed consent}

Informed consent has been obtained from all individuals included in this study and their parents (if the participant was under 18 years of age). 


\section{HUMAN MOVEMENT}

A.M.J. Mero, K. Häkkinen, H. Kyröläinen, A.A. Mero, Effects of training on bone

\section{Results}

Training

The training volume is presented in Tables 1 and 2 . The control group in study 2 performed physical activity (gymnastics, cycling, ball games, and walking), 3 hours a week on average.

Blood variables and physical performance in study 1

In younger boys and girls, significant increases were noticed in the concentrations of osteocalcin $(p<0.01)$, testosterone ( $p$ : from $<0.05$ to 0.01 ), and cortisol $(p<0.01)$ during the 8-week period (Table 3). The 20-m sprint performance improved in girls $(p<0.01)$ and CMJ improved in boys $(p<0.001)$. Gender differences were found in all other variables except serum osteocalcin and cortisol.

\section{Blood variables and physical performance}

in study 2

In older boys and girls, significant increases after 6 months of training were noticed in osteocalcin $(p<$ 0.01 ), osteocalcin/TRAP5b ratio ( $p$ : from $<0.01$ to 0.001 ), and standing 5-jump ( $p$ : from $<0.05$ to 0.01 ) (Table 4), whereas serum TRAP5b decreased both in boys $(p<0.05)$ and in girls $(p<0.01)$. Boys improved their results in 20 -m sprint $(p<0.05)$, standing 5 -jump $(p<0.01)$, and Cooper test run $(p<0.05)$. Girls improved significantly only their standing 5 -jump performance $(p<0.05)$.
Table 1. Training volume during the 8 -week training period in study 1 (means)

\begin{tabular}{lrc}
\hline Item & Total & Per week \\
\hline Training hours $(n)$ & 48 & 6 \\
Total training sessions $(n)$ & 32 & 4 \\
Event-specific sessions $(n)$ & 16 & 2 \\
Strength sessions $(n)$ & 8 & 1 \\
Endurance sessions $(n)$ & 8 & 1 \\
Plyometric sessions $(n)$ & 16 & 2 \\
Period 1 (contacts, $n)$ & 900 & 112 \\
Period 2 (contacts, $n$ ) & 600 & 75 \\
Period 3 (contacts, $n$ ) & 450 & 56 \\
Period 4 (contacts, $n$ ) & 250 & 31 \\
\hline
\end{tabular}

Plyometric sessions were included either in event-specific sessions or in strength sessions. Each period lasted 2 weeks. All subjects did the same amount of supervised training.

Table 2. Training volume during the 6 -month training period in study $2($ mean $\pm S D)$

\begin{tabular}{lcc}
\hline Item & Total & Per week \\
\hline Training hours $(n)$ & $286 \pm 44$ & $12 \pm 2$ \\
Total training sessions $(n)$ & $177 \pm 29$ & $7 \pm 2$ \\
Event-specific sessions $(n)$ & $87 \pm 43$ & $3 \pm 1$ \\
Strength sessions $(n)$ & $26 \pm 19$ & $1 \pm 1$ \\
Plyometric sessions $(n)$ & $61 \pm 23$ & $2 \pm 1$ \\
Contacts $(n)$ & $1850 \pm 445$ & $77 \pm 21$ \\
Speed sessions $(n)$ & $34 \pm 22$ & $1 \pm 1$ \\
Aerobic running $(\mathrm{km})$ & $890 \pm 486$ & $37 \pm 19$ \\
Off days $(n)$ & $42 \pm 10$ & $2 \pm 1$ \\
Sick days $(n)$ & $11 \pm 9$ & $1 \pm 1$ \\
\hline
\end{tabular}

Table 3. Mean $( \pm S D$ ) values of the primary variables in boys and girls before and after the 8 -week training period in study 1

\begin{tabular}{lcccc}
\hline \multirow{2}{*}{ Variable } & \multicolumn{2}{c}{ Boys } & \multicolumn{2}{c}{ Girls } \\
\cline { 2 - 5 } & Before & After & Before & After \\
\hline Osteocalcin $(\mathrm{ng} / \mathrm{ml})$ & $27.3 \pm 18.9^{* *}$ & $44.2 \pm 23.5$ & $19.1 \pm 9.1^{* *}$ & $31.4 \pm 14.0$ \\
Serum TRAP5b (U/l) & $17.0 \pm 6.4$ & $17.4 \pm 6.1 \dagger$ & $11.0 \pm 5.0$ & $10.9 \pm 4.8$ \\
Osteocalcin/TRAP5b & $2.0 \pm 1.8^{*}$ & $2.9 \pm 2.0$ & $1.9 \pm 0.8^{*}$ & $2.6 \pm 0.8$ \\
Testosterone (nmol/l) & $11.3 \pm 5.7^{* *}$ & $15.3 \pm 7.4 \dagger \dagger$ & $0.8 \pm 0.7^{*}$ & $1.1 \pm 0.6$ \\
Cortisol (nmol/l) & $451 \pm 82^{* *}$ & $561 \pm 98$ & $397 \pm 70^{* *}$ & $519 \pm 121$ \\
Testosterone/cortisol $\left(\times 10^{-2}\right)$ & $2.7 \pm 1.5$ & $2.9 \pm 1.5 \dagger \dagger$ & $0.2 \pm 0.2$ & $0.2 \pm 0.1$ \\
20-m sprint time $(\mathrm{s})$ & $2.44 \pm 0.16$ & $2.43 \pm 0.17 \dagger$ & $2.62 \pm 0.10^{* *}$ & $2.58 \pm 0.14$ \\
CMJ (cm) & $36.1 \pm 4.8^{* * *}$ & $38.8 \pm 5.4 \dagger$ & $31.6 \pm 2.8$ & $32.8 \pm 2.8$ \\
\hline
\end{tabular}

TRAP5b - tartrate-resistant acid phosphatase isoenzyme 5b, CMJ - countermovement jump

Difference between the status before and after: ${ }^{*} p<0.05,{ }^{* *} p<0.01,{ }^{* * *} p<0.001$

Difference between boys and girls in mean values of the status before and after: $\dagger p<0.05, \dagger \dagger p<0.001$ 
Table 4. Mean $( \pm S D)$ values of the primary variables in boys and girls before and after the 6-month training period in study 2

\begin{tabular}{|c|c|c|c|c|c|c|c|c|}
\hline \multirow{2}{*}{ Variable } & \multicolumn{2}{|c|}{ Athletics boys } & \multicolumn{2}{|c|}{ Athletics girls } & \multicolumn{2}{|c|}{ Control boys } & \multicolumn{2}{|c|}{ Control girls } \\
\hline & Before & After & Before & After & Before & After & Before & After \\
\hline Osteocalcin (ng/ml) & $15.3 \pm 6.4^{* *}$ & $23.2 \pm 8.4 \dagger \dagger$ & $8.1 \pm 3.7^{* *}$ & $11.5 \pm 5.3$ & $6.1 \pm 3.3$ & $7.0 \pm 3.5^{* *}$ & $3.3 \pm 1.7$ & $4.6 \pm 2.0$ \\
\hline Serum TRAP5b (U/l) & $7.3 \pm 4.3^{*}$ & $6.4 \pm 3.5+\dagger$ & $3.9 \pm 1.6^{* *}$ & $3.3 \pm 1.5$ & $4.1 \pm 2.3$ & $4.3 \pm 2.3^{* *}$ & $1.8 \pm 0.8$ & $1.9 \pm 0.7$ \\
\hline Osteocalcin/TRAP5b & $2.7 \pm 1.5^{* *}$ & $4.2 \pm 2.1$ & $2.2 \pm 0.8^{* * *}$ & $3.5 \pm 1.1$ & $1.5 \pm 1.4$ & $1.6 \pm 1.5$ & $1.8 \pm 0.9$ & $2.4 \pm 2.0$ \\
\hline Testosterone (nmol/l) & $16.7 \pm 4.4$ & $17.6 \pm 4.3+\dagger$ & $1.2 \pm 0.4$ & $1.1 \pm 0.3$ & $17.8 \pm 3.3$ & $18.7 \pm 4.1 \dagger \dagger$ & $1.2 \pm 0.8$ & $1.4 \pm 0.9$ \\
\hline Cortisol (nmol/l) & $521 \pm 130$ & $505 \pm 140 \dagger$ & $729 \pm 160$ & $726 \pm 206$ & $405 \pm 73$ & $501 \pm 134$ & $445 \pm 120$ & $516 \pm 110$ \\
\hline $\begin{array}{l}\text { Testosterone/cortisol } \\
\qquad\left(\times 10^{-2}\right)\end{array}$ & $3.2 \pm 3.4$ & $3.5 \pm 3.1 \dagger \dagger$ & $0.2 \pm 0.3$ & $0.2 \pm 0.2$ & $4.4 \pm 3.9$ & $3.7 \pm 2.9+\dagger$ & $0.3 \pm 0.3$ & $0.3 \pm 0.4$ \\
\hline 20-m sprint (s) & $2.31 \pm 0.20^{*}$ & $2.26 \pm 0.17 \dagger \dagger$ & $2.54 \pm 0.13$ & $2.52 \pm 0.13$ & & & & \\
\hline Standing 5-jump (m) & $13.20 \pm 0.96^{* *}$ & $13.53 \pm 1.06 \dagger \dagger$ & $11.11 \pm 0.89^{*}$ & $11.36 \pm 0.91$ & & & & \\
\hline Cooper run (m) & $3173 \pm 407^{*}$ & $3272 \pm 134 \dagger \dagger$ & $2598 \pm 202$ & $2627 \pm 211$ & & & & \\
\hline
\end{tabular}

TRAP5b - tartrate-resistant acid phosphatase isoenzyme $5 \mathrm{~b}$

Difference between the status before and after: ${ }^{*} p<0.05,{ }^{*} p<0.01,{ }^{* *} p<0.001$

Difference between boys and girls in mean values of the status before and after: $\dagger p<0.01, \dagger \dagger p<0.001$

Relationships between blood variables, age, gender, and performance

In athletic boys in study 2 , the individual changes in osteocalcin during the 6-month training were correlated significantly with the number of training sessions $(r=0.54, p<0.05)$, and the changes in TRAP5b were significantly correlated with the number of training hours $(r=0.52, p<0.05)$. In the combined male and female athletic groups, the individual changes in standing 5-jump were correlated significantly with the changes in $20-\mathrm{m}$ flying sprint time $(r=-0.68$, $p<0.001)$. The changes in the Cooper endurance running test were correlated significantly with the running kilometres $(r=0.62, p=0.001)$.

In the combined group of all subjects from the 2 studies, the correlation coefficient between TRAP5b and age was high and strongly significant $(r=-0.63$, $p<0.001, n=57$ ). In addition, TRAP5b and age associated highly in boys $(r=-0.59, p<0.001, n=29)$ and girls $(r=-0.77, p<0.001, n=28)$. No significant correlations were found between osteocalcin, testosterone, and age.

\section{Discussion}

The present results showed that serum osteocalcin increased in pubertal 14-year-old boys (70\%) and girls (64\%) during the 8 -week intensive training period including increased plyometric jumping exercises. In turn, serum TRAP5b showed no changes during training, but its basic level was 56\% higher in boys compared with girls. Post-pubertal 17-year-old athletic boys and girls also presented large increases in osteocalcin during the 6 months (by $52 \%$ and $42 \%$, respectively). The levels were clearly higher than the nonsignificant increases noted in the controls. TRAP5b decreased both in athletic boys (12\%) and girls (15\%), but the controls exhibited no changes. The osteocalcin/TRAP5b ratio increased in both age groups during the training periods.

\section{Training and physical performance}

In younger athletic boys and girls, the training volume included 4 supervised sessions (6 hours) per week. It is an average amount in track and field training at that age in Finland. The intensive plyometric training was conducted twice per week. It was a large increase because earlier the participants had trained eventspecific jumping (long jump, triple jump, high jump) only $0-1$ time per week. Only minor injuries in knee and back were observed during their training. The performance in sprinting and jumping (CMJ) improved slightly as expected during the 8-week period.

The post-pubertal athletic groups trained with their own training plans during this study. The total volume of training was, on average, 7 training sessions per week (12 training hours), which is almost double compared with the younger groups. The number of plyometric jumping exercises sessions was 2 per week, as in the younger ones. Individual differences in their training modes were noticed as expected. The sprinters, jumpers, and throwers had more variability in the content of their training sessions (e.g. stretching and mobility sessions, event technique) than the pre- 
A.M.J. Mero, K. Häkkinen, H. Kyröläinen, A.A. Mero, Effects of training on bone

sent endurance runners, who performed more kilometres for running. It is also difficult to make any strong conclusions regarding the training volume of the present Finnish young athletes because, as far as we know, there are no published scientific results on training volumes and contents in other countries. Anyway, sprinting speed, power production, and endurance running (Cooper test) improved in both sexes, but in overall, boys improved their physical performance slightly more than girls did. In the combined male and female athletic group, the increase in the standing 5 -jump correlated with the decrease in the 20-m flying sprint time; on the other hand, the Cooper endurance running time was better when the running kilometres increased. These correlative results suggest that training programming was successful in these athletes.

\section{Bone formation and resorption}

The present values of osteocalcin imply that bone formation metabolism was very active in both study groups. When comparing the mean values of athletic boys and girls, one can observe that the highest content of osteocalcin was at the age of 14 years. Boys presented a mean value of $36.9 \mathrm{ng} / \mathrm{ml}$, which is $91 \%$ higher than that of $19.3 \mathrm{ng} / \mathrm{ml}$ at the age of 17 years. The respective values for girls were $25.3 \mathrm{ng} / \mathrm{ml}$ and $9.8 \mathrm{ng} / \mathrm{ml}$ and the difference equalled $158 \%$. The osteocalcin values were clearly lower in the controls $(6.6 \mathrm{ng} / \mathrm{ml}$ and $4.0 \mathrm{ng} / \mathrm{ml})$ compared with the present 17-year-old athletic participants. The Finnish reference values vary from 2 to $22 \mathrm{ng} / \mathrm{ml}$ in all age groups [19]. It is generally known that the pace of bone mineral acquisition is similar to that of linear bone growth, with rapid gains in infancy, slower increases during childhood, and major gains during puberty (e.g. [20]). Approximately, half of the peak bone mass is gained during the teenage years, making this a critical period for optimizing conditions for skeletal health. Peak bone mass is the maximum amount of bone a person has during the lifetime. It typically occurs in the early 20 s in females and late 20s in males [21]. Peak bone mass is typically lower in females than in males. Unfortunately, we did not measure bone mineral density, which is a way to determine bone mass. Largely, peak bone mass is predetermined by heritable factors. Family and twin studies suggest that $60-80 \%$ of the differences in peak bone mass between individuals can be attributed to genetics [22, 23]. The present results are in line with previous studies [8] indicating that osteocalcin increases during training. In athletics boys, the change in osteocalcin during the present 6 months was significantly and positively correlated with the number of training sessions. Bone strength increases more with training that includes high impact forces, such as sprinting, jumping, and weightlifting [24, 25]. Consequently, it can be concluded that bone formation metabolism in young athletes is very active, especially during puberty, but also in the post-pubertal phase, giving rapid gains to peak bone mass.

Serum TRAP5b concentrations were higher in the younger age group. This confirms earlier results indicating that in the normal growing phase in children, there are high resorption values [8]. In our study, the TRAP5b values were somewhat higher than those observed in 20-44-year-old women and men (mean values: 2.9 and $4.0 \mathrm{U} / 1$, respectively) [26]. The relationship between TRAP5b and age was also confirmed with strong significant negative correlation coefficients both in the combined group of all subjects $(n=57)$ and separately in boys and girls. In the 17-year-old athletes, the TRAP5b values decreased during training but it was surprising that the controls showed no changes. In any case, all values were quite low and the osteocalcin/TRAP5b ratio increased in both training age groups. Only a few subjects presented decreases in the ratio and they were all endurance runners. This finding was not uncommon, since studies (e.g. [27]) have shown that high-class long distance runners have low bone mineral density, which increases the risk of bone-related injuries. Long lasting endurance performances tend to elevate bone resorption markers and decrease bone formation markers, thus preventing osteoblasts from forming new bone tissue [27]. This was not a problem for most of the subjects in the present study as osteocalcin increased and TRAP5b decreased significantly during the 6-month period. It suggests that quite intensive training in these age phases possibly affects bone metabolism.

\section{Testosterone/cortisol ratio}

In the present younger age group, the serum testosterone levels strongly increased during the 8 weeks, which is quite normal in pubertal boys and girls. Many individuals even showed values that were at the levels of adults (men: $10-38 \mathrm{nmol} / 1$, women: $0.4-2.0 \mathrm{nmol} / \mathrm{l}$ [28]). This process is affected by both growing and training. Unfortunately, we did not have a control group. Also, the cortisol levels increased, which indicates that training was quite intensive towards the summer competition season. However, the testosterone/ cortisol ratio suggests that the participants were well 
within the values in good anabolic/catabolic ratio [11]. The 17-year-old boys and girls were probably in the post-pubertal phase because, for instance, they all exhibited testosterone levels within the adult values. The cortisol values were higher in the athletic girls than in the athletic boys. This may be partly explained by an overall stress. Cortisol concentration is affected by both physical stress and mental stress (e.g. [11]). Perhaps the increase in cortisol in the girls was related to high mental stress they may have experienced, e.g. owing to important exams in the high school or some other factors in their lives. The testosterone/cortisol ratio was at the same level before and after the intervention, indicating that the participants in all groups were within normal values. When comparing the osteocalcin/TRAP5b ratio and testosterone/cortisol ratio between the 2 age groups, slight increases in the ratios could be observed. It suggests that the anabolic condition might have improved, although the training volume was much larger in the older group. Testosterone concentration did not correlate significantly with osteocalcin, which could imply that these anabolic metabolites may operate separately in the human body.

\section{Conclusions}

The present study, which used osteocalcin and TRAP $5 b$ as bone formation and resorption markers, showed that bone turnover was anabolic after both training periods. TRAP5b decreases at the age of 14-17 years, which may suggest that bone turnover slows down. In practice, it is important to add plyometrics and other strength training to the training plans of young athletes, regardless of their events, to increase their bone metabolism and muscle strength. We did not collect food diaries, but we must remember, as Amato et al. [29] pointed out, that nutrition and physical activity interact with each other and they both affect bone metabolism.

\section{Disclosure statement}

No author has any financial interest or received any financial benefit from this research.

\section{Conflict of interest}

The authors state no conflict of interest.

\section{References}

1. Seibel MJ. Biochemical markers of bone turnover: part I: biochemistry and variability. Clin Biochem Rev. 2005;26(4):97-122.

2. Banfi G, Lombardi G, Colombini A, Lippi G. Bone metabolism markers in sports medicine. Sports Med. 2010;
40(8):697-714; doi: 10.2165/11533090-00000000000000.

3. Hauschka PV, Lian JB, Cole DE, Gundberg CM. Osteocalcin and matrix Gla protein: vitamin K-dependent proteins in bone. Physiol Rev. 1989;69(3):990-1047; doi: 10.1152/physrev.1989.69.3.990.

4. Maïmoun L, Coste O, Puech A-M, Peruchon E, Jaussent A, Paris F, et al. No negative impact of reduced leptin secretion on bone metabolism in male decathletes. Eur J Appl Physiol. 2008;102(3):343-351; doi: 10.1007/ s00421-007-0592-7.

5. Lee NK, Karsenty G. Reciprocal regulation of bone and energy metabolism. Trends Endocrinol Metab. 2008; 19(5):161-166; doi: 10.1016/j.tem.2008.02.006.

6. Krabbe S, Hummer L, Christiansen C. Longitudinal study of calcium metabolism in male puberty. II. Relationship between mineralization and serum testosterone. Acta Paediatr Scand. 1984;73(6):750-755; doi: 10.1111/j.1651-2227.1984.tb17770.x.

7. Gilsanz V, Gibbens DT, Roe TF, Carlson M, Senac MO, Boechat MI, et al. Vertebral bone density in children: effect of puberty. Radiology. 1988;166(3):847-850; doi: 10.1148/radiology.166.3.3340782.

8. López MR, Olmedillas H, de la Fuente FP, GómezCabello A, González-Agüero A, Casajús JA, et al. Bone metabolism in child and adolescent athletes: a systematic review [in Spanish]. Nutr Hosp. 2017;34(5):14691481; doi: 10.20960/nh.1109.

9. Halleen JM, Alatalo SL, Suominen H, Cheng S, Janckila AJ, Väänänen HK. Tartrate-resistant acid phosphatase 5b: a novel serum marker of bone resorption. J Bone Miner Res. 2000;15(7):1337-1345; doi: 10.1359/ jbmr.2000.15.7.1337.

10. Yaziji H, Janckila AJ, Lear SC, Martin AW, Yam LT. Immunohistochemical detection of tartrate-resistant acid phosphatase in non-hematopoietic human tissues. Am J Clin Pathol. 1995;104(4):397-402; doi: 10.1093/ ajcp/104.4.397.

11. Häkkinen K, Pakarinen A, Alén M, Komi PV. Serum hormones during prolonged training of neuromuscular performance. Eur J Appl Physiol Occup Physiol. 1985;53(4):287-293; doi: 10.1007/bf00422840.

12. Durnin JV, Rahaman MM. The assessment of the amount of fat in the human body from measurements of skinfold thickness. Br J Nutr. 1967;21(3):681-689; doi: 10.1079/bjn19670070.

13. Mero A, Komi PV. EMG, force, and power analysis of sprint-specific strength exercises. J Appl Biomech. 1994;10(1):1-13; doi: 10.1123/jab.10.1.1.

14. Cooper KH. A means of assessing maximal oxygen intake: correlation between field and treadmill testing. JAMA. 1968;203(3):201-204; doi: 10.1001/jama.1968. 03140030033008.

15. Keskinen KL, Häkkinen K, Kallinen M (eds.). Handbook of fitness testing [in Finnish]. Tampere: TammerPress Ltd.; 2004. 


\section{HUMAN MOVEMENT}

A.M.J. Mero, K. Häkkinen, H. Kyröläinen, A.A. Mero, Effects of training on bone

16. Viitasalo JT, Aura O. Seasonal fluctuations of force production in high jumpers. Can J Appl Sport Sci. 1984; 9(4):209-213.

17. Komi PV, Bosco C. Utilization of stored elastic energy in leg extensor muscles by men and women. Med Sci Sports. 1978;10(4):261-265.

18. Rogers RS, Dawson AW, Wang Z, Thyfault JP, Hinton PS. Acute response of plasma markers of bone turnover to a single bout of resistance training or plyometrics. J Appl Physiol. 2011;111(5):1353-1360; doi: 10.1152/japplphysiol.00333.2011.

19. Huslab 2018. Osteocalcin in serum [in Finnish]. Available from: https://huslab.fi/cgi-bin/ohjekirja/tt_ show.exe?assay $=3594 \&$ terms $=$ osteo .

20. Bonjour JP, Chevalley T, Ammann P, Slosman D, Rizzoli R. Gain in bone mineral mass in prepubertal girls 3.5 years after discontinuation of calcium supplementation:afollow-upstudy.Lancet.2001;358(9289):12081212; doi: 10.1016/S0140-6736(01)06342-5.

21. Avdagić SC, Barić IC, Keser I, Cecić I, Satalić Z, Bobić J, et al. Differences in peak bone density between male and female students. Arh Hig Rada Toksikol. 2009; 60(1):79-86; doi: 10.2478/10004-1254-60-2009-1886.

22. Kelly PJ, Eisman JA, Sambrook PN. Interaction of genetic and environmental influences on peak bone density. Osteoporos Int. 1990;1(1):56-60; doi: 10.1007/ BF01880417.

23. Krall EA, Dawson-Hughes B. Heritable and life-style determinants of bone mineral density. J Bone Miner Res. 1993;8(1):1-9; doi: 10.1002/jbmr.5650080102.

24. Lester ME, Urso ML, Evans RK, Pierce JR, Spiering BA, Maresh CM, et al. Influence of exercise mode and osteogenic index on bone biomarker responses during short-term physical training. Bone. 2009;45(4):768776; doi: 10.1016/j.bone.2009.06.001.

25. Guadalupe-Grau A, Perez-Gomez J, Olmedillas H, Chavarren J, Dorato C, Santana A, et al. Strength training combined with plyometric jumps in adults: sex differences in fat-bone axis adaptations. J Appl Physiol. 2009; 106(4):1100-1111; doi:10.1152/japplphysiol.91469.2008.

26. Minkin C. Bone acid phosphatase: tartrate-resistant acid phosphatase as a marker of osteoclast function. Calcif Tissue Int. 1982;34(3):285-290; doi: 10.1007/BF024 11252.

27. Kerschan-Schindl K, Thalmann M, Sodeck GH, Skenderi K, Matalas AL, Grampp S, et al. A 246-km continuous running race causes significant changes in bone metabolism. Bone. 2009;45(6):1079-1083; doi: 10.1016/ j.bone.2009.07.088.

28. Huslab 2019. Testosterone in serum [in Finnish]. Available from: https://huslab.fi/cgi-bin/ohjekirja/tt_show. exe?assay $=2735 \&$ terms $=$ testosterone.

29. Amato A, Baldassano S, Cortis C, Cooper J, Proia P. Physical activity, nutrition, and bone health. Hum Mov. 2018;19(4):1-10; doi: 10.5114/hm.2018.77318. 